Table 2 Concentrations of D-dimers in blood from 15 preterm infants and 45 born at full term

\begin{tabular}{|c|c|c|c|}
\hline \multirow{2}{*}{$\begin{array}{l}\text { Concentrations of } \\
\text { D-dimers }(\mathrm{mg} / \mathrm{l})\end{array}$} & \multicolumn{3}{|c|}{ No (\%) of infants } \\
\hline & $\begin{array}{l}\text { Born at } \\
\text { full term } \\
(n=45)\end{array}$ & $\begin{array}{l}\text { Born } \\
\text { preterm } \\
(n=15)\end{array}$ & $\begin{array}{l}\text { Total } \\
(n=60)\end{array}$ \\
\hline $\begin{array}{l}<0 \cdot 25 \\
0 \cdot 25-0.5 \\
0 \cdot 5-1 \\
1-2 \\
2-4\end{array}$ & $\begin{aligned} 24 & (53) \\
14 & (31) \\
6 & (13) \\
1 & (2) \\
0 & \end{aligned}$ & $\begin{array}{l}7(47) \\
2(13) \\
2(13) \\
2(13) \\
2(13)\end{array}$ & $\begin{array}{c}31(52) \\
16(27) \\
8(13) \\
3(5) \\
2(3)\end{array}$ \\
\hline
\end{tabular}

All D-dimers concentrations in the pregnant mothers were $<0.25 \mathrm{mg} / \mathrm{l}$.

\section{Discussion}

Measurement of D-dimers concentrations has been suggested as an alternative to measuring fibrin/fibrinogen degradation products, as they have been shown to be more sensitive. and specific and can be measured in as little as $10 \mu \mathrm{l}$ of plasma. Normal adults have plasma concentrations of $<0.25 \mathrm{mg} / \mathrm{l}$. Using the more sensitive ELISA antibody test, mildly increased concentrations have also been found in normal pregnant women. ${ }^{5}$ We were unable to confirm this finding in women in labour in whom D-dimers were measured by the latex agglutination technique.

The results of measurements of D-dimers in infants show that the range of plasma concentrations found in normal adults does not apply either to preterm infants or to those born at full term, as about half the infants had values outside the accepted adult range.

The reason for the increased concentrations of D-dimers in these infants is unknown. Trans- placental passage is unlikely, because the concentrations found in 17 pregnant mothers before delivery were all less than $0.25 \mathrm{mg} / \mathrm{l}$. Other possible explanations are that D-dimers may represent low grade activation of the coagulation system as a result of the circulatory adjustments of closure of the ductus venosus and ductus arteriosus after birth, or perhaps there is delayed renal clearance of D-dimers in the newborn. Fibrin/fibrinogen degradation products have also been found in $65 \%$ of normal term infants. ${ }^{6}$ The results of coagulation screening tests in infants born at full term were similar to those in normal adults.

We conclude that newborn infants have ranges of concentrations for D-dimers that are different from adults, and therefore caution is necessary in their use and interpretation.

I R B Hudson is supported by a grant from the Scottish Hospitals Endowment Research Trust. We thank the technical staff of the haematology department for their help in analysing the specimens and Miss $\mathrm{K}$ Black for typing the manuscript.

1 Lane DA, Preston FE, VanRoss ME, Kakkar VV. Characterisation of serum fibrinogen and fibrin fragments produced during disseminated intravascular coagulation. $\mathrm{Br}$ f Haematol 1978;40:609-15.

2 Gaffney PJ, Perry MJ. Unreliability of current serum fibrin degradation product (FDP) assays. Thromb Haemost 1985; 53:301-2.

3 Greenberg CS, Devine DV, McCree KM. Measurement of plasma fibrin D-dimer levels with the use of a monoclonal antibody coupled to latex beads. Am f Clin Pathol 1987; 87:94-100.

4 Elms JM, Bunce IH, Bundesen PG, et al. Rapid detection of cross-linked fibrin degradation products in plasma using monoclonal antibody-coated latex particles. Am f Clin Pathol 1986;85:360-4.

5 Ballegeer V, Mombaerts P, Declecrek PJ, Spitz B, VonAssche FA, Collen D. Fibrinolytic response to venous VonAssche FA, Collen D. Fibrinolytic response to venous
occlusion and fibrin fragment D-dimer levels in normal and complicated pregnancy. Thromb Haemost 1987; 58:1030-2

6 Stiehm, Clantanoft. Split products of fibrin in the serum of newborns. Pediatrics 1969;43:770-80.

\section{St Mary's Hospital, Manchester T Mohammed M Maresh C P Sibley R D H Boyd \\ Correspondence to: Dr T Mohammed, Department of Child Health, Research Floor, Manchester M13 0JH.}

Accepted 7 September 1989

\title{
Absent maternofetal potassium gradient at term
}

\author{
T Mohammed, M Maresh, C P Sibley, R D H Boyd
}

\begin{abstract}
Mean (SE) umbilical venous plasma potassium concentrations at $5 \cdot 5,10,20$, and 30 minutes after the start of laparotomy at term were $4.75(0.15), 5.95(0.26), 6.81(0.23)$, and $7.59(0.81) \mathrm{mmol} / \mathrm{kg}$ plasma water. Maternal peripheral venous plasma concentrations were $4 \cdot 30(0 \cdot 13)$ before and $4 \cdot 26(0 \cdot 23)$ $\mathrm{mmol} / \mathrm{kg}$ plasma water after laparotomy. Plasma calcium concentration in maternal and cord blood did not change significantly.
\end{abstract}

A reported higher umbilical than maternal venous plasma concentration of potassium at full term in the human ${ }^{12}$ has been taken as prima facie evidence that the ion is actively transported across human placenta. ${ }^{3}$ We have reinvestigated the human maternofetal venous plasma gradient reported with particular attention to time of sampling and find that, as in the rat, ${ }^{4}$ the umbilical plasma concentration rises immediately after delivery. It appears that the reported concentration difference is likely to be artefactual.

\section{Subjects and methods}

After ethical approval and maternal consent, 19 pregnant women undergoing elective caesarean section for previous section were selected on days that were convenient for study. A maternal peripheral venous blood sample of about 5 to $10 \mathrm{ml}$, from a large vein usually in the antecubital fossa using a 21 gauge needle, was taken when the patient entered the anaesthetic room about 30 minutes before surgery. A further maternal sample was taken at the end of the operation about 60 minutes after the first.

Timing of umbilical sampling was related to 
abdominal skin incision (time 0). At birth (mean (SE) 5 (1) minutes) the baby was lifted out and the cord was clamped in three places with clamp 1 being very near to the infant's umbilicus. Clamp 2 was applied about $5 \mathrm{~cm}$ away from this. Clamp 3 was applied very near to the placenta. This arrangement meant that virtually the whole length of cord was between clamps 2 and 3 . The cord was cut between clamps 1 and 2 to deliver the infant. At this time ( 5.5 (1) minutes from incision) 3 to $5 \mathrm{ml}$ of blood was withdrawn immediately from the umbilical artery and vein between clamps 2 and 3. The placenta was then removed with the clamps in situ. Further blood samples were taken from between clamps 2 and 3 and from a chorionic plate vein at timed intervals approximately 10, 20, and 30 minutes from abdominal incision. All blood samples were centrifuged immediately (within two minutes) after collecting and plasma was separated. An aliquot of the plasma was dried to constant weight at $80^{\circ} \mathrm{C}$ to determine plasma water content.

For potassium determinations, aliquots of plasma were diluted 200 fold in water and potassium concentration was measured by atomic absorption spectroscopy on a Perkin Elmer atomic absorption spectrophotometer. The rest of the plasma was frozen for subsequent determination of total calcium using the arsenazo-3 method in the routine biochemical laboratory. Concentrations are expressed as $\mathrm{mmol} / \mathrm{kg}$ plasma water.

\section{Results}

All concentrations are expressed as mean (SE). Concentrations of potassium in cord venous plasma water at $5.5,10,20$, and 30 minutes after incision were $4 \cdot 75(0 \cdot 15), 5 \cdot 95(0 \cdot 26), 6 \cdot 81$ $(0.23)$, and $7.59(0.81) \mathrm{mmol} / \mathrm{kg}$ plasma water. Maternal plasma potassium concentrations were unchanged after laparotomy $(4 \cdot 30(0 \cdot 13)$ before and $4.26(0.23)$ after $)$. Concentrations of potassium in chorionic venous plasma water at 10,20 , and 30 minutes after incision were $8 \cdot 2(0 \cdot 9), 8 \cdot 9(1 \cdot 4)$, and $11 \cdot 6(2 \cdot 2)$, respectively

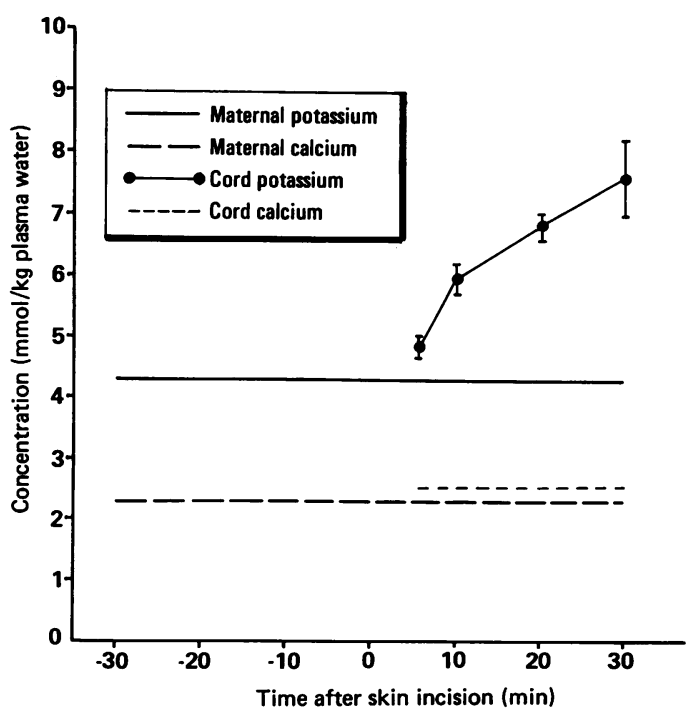

Mean (SE) potassium and calcium concentrations in plasma water mmol/kg water as a function of time of sampling. Time of abdominal skin incision taken as time 0 .
The first cord sample had a mean concentration $0.37(0 \cdot 15) \mathrm{mmol} / \mathrm{kg}$ more than mean maternal value. This difference rose sharply with time (figure). Values from chorionic plate veins were substantially higher. Values uncorrected for plasma water $(\mathrm{mmol} / \mathrm{l})$ showed a similar rise.

The values for calcium confirmed the previously observed maternofetal difference (maternal $2.30(0.05)$, fetal $2.54(0.05) \mathrm{mmol} / \mathrm{l} / \mathrm{kg})$. There was no significant increase in cord calcium concentrations with time.

\section{Discussion}

The mean value on cord blood sample 4.5 minutes after delivery, and approximately 10 minutes after incision of the maternal abdominal wall, was $1.7(0.2) \mathrm{mmol} / \mathrm{kg}$ plasma water higher than maternal; this is comparable with that reported in careful previous studies. ${ }^{2}$ Five and a half minutes after abdominal incision and immediately after cord clamping, however, the cord venous concentration, although still significantly different, was only $0.37(0.15)$ $\mathrm{mmol} / \mathrm{kg}$ higher than maternal. It was impossible under the conditions of our study to sample cord blood at the time of abdominal incision but extrapolation by eye of the cord venous concentrations plotted in the figure back to time 0 suggest that it is highly unlikely that cord venous plasma potassium at term at the start of caesarean section is truly higher than maternal in well nourished healthy women before labour. This is probably also true in mid gestation. 5 The rise in delayed samples after cord clamping suggests leakage of intracellular red cell potassium into plasma and the greater rise seen in blood from chorionic plate vessels suggests leakage from placental parenchyma.

Fetal accretion of potassium is high and net transplacental potassium fluxes are comparable with those of sodium and chloride. ${ }^{3}$ Its transport must be either diffusional or active. As no significant maternofetal potential difference has been reported in the human at term ${ }^{2}$ its cord venous plasma water concentration would have to be below maternal arterial to allow for diffusional accretion. Extrapolation to time $\mathbf{0}$ in the figure suggests this is possible. Such diffusional transport would probably be via channels, perhaps specific, but in any case too small to accommodate the divalent ion calcium whose previously reported maternofetal concentration difference at term is confirmed here. ${ }^{2}$ Alternatively active net transport of potassium must be controlled with sufficient precision to maintain maternofetal concentrations in close proximity at term. Analogy with the haemochorial placenta of the rat leads us to support the latter hypothesis, ${ }^{6}$ but it should be noted that cord plasma concentration differences as reported here cannot be used as evidence to support such a belief.

We gratefully acknowledge the support of the North West regional health authority for support of TM and an Endowment of the National Fund for Research into Crippling Diseases for other expenses.

Mellor DJ, Cockburn F, Lees MM, Blagden A. Distribution of ions and electrical potential differences between mother and fetus in the human at term. Fourmal of Obstetrics and Gynaecology of the British Commonwealth 1969;76:993-8. 2 Faber JJ, Thornburg KL. The forces that drive inert solutes and water across the epitheliochorial placentae of the sheep 
and the goat and the haemochorial placentae of the rabbit and the guinea pig. Placenta 1981;suppl 2: 203-14.

3 Canning J, Boyd RDH. Mineral and water exchanged between mother and fetus. In: Beard RW, Nathanielsz PW eds. Fetal physiology and medicine. New York: Marcel Dekker, 1984:481-509.

4 Fantel AG. Fetomaternal potassium relations in the fetal rat on the twentieth day of gestation. Pediatr Res 1975;9: 527-30.
5 Moniz CF, Nicolaides KH, Bamforth FJ, Rodeck $\mathrm{CH}$. Normal reference ranges for biochemical substances relating to renal, hepatic, and bone function in fetal and maternal to renal, hepatic, and bone function in etal and maternal plasma the

6 Dancis J, Springer D. Fetal homeostasis in maternal malnutrition: potassium and sodium deficiency in rats. Pediatr Res 1974;4:345-51.

\section{Anatomy and development of the fontanelle}

M Sundaresan, $M$ Wright, A B Price

\begin{abstract}
Anterior fontanelles from 19 fetuses over a range of gestational ages (from 8 weeks to full term) were obtained to study the anatomy and development in relation to the application of the principles of fontanometry. The most important feature was the development of an elastic membrane by 23 weeks' gestation; a subcutaneous layer of fat had appeared by 28 weeks' gestation.
\end{abstract}

The applanation principle can be applied to a method of measuring intracranial pressure, and the anterior fontanelle is the usual site. Inaccuracies in measurement may arise from variations in the elasticity of the fontanelle at different stages of gestation, or from there being too small a surface on which to fix the sensor, which is at least $1 \mathrm{~cm}$ in diameter. This study was undertaken to try and detect structural changes that might explain inaccuracies in fontanometry. Many methods have been used to measure fontanelle size and we used a modification of Scammon's technique.

\section{Material and methods}

Nineteen fontanelles were examined over a developmental period ranging from a fetus of 8 weeks' gestation to a full term neonate who died four weeks after birth

The surface area of the non-macerated fontanelle was measured by placing soft paper over the previously dried skin, palpating the corners of the fontanelles and rubbing over these corners and edges with a soft pencil. This produced a crude 'brass rubbing' of the outline of the fontanelle. This was transferred to graph paper by pricking through it with a pin. The squares within the outline were counted, and the area in square centimetres recorded. ${ }^{2}$ In addition, the shortest diameter of each fontanelle (Elasser's diameter) was measured, as during fontanometry it is important that the sensor does not touch the edges of the fontanelle.

Blocks for microscopy were taken by excising the fontanelle together with a $0.5 \mathrm{~cm}$ rim of bone. A slice was trimmed across the middle of the block to include bone at either side. In the case of a necropsy fetus a coronal skin incision was made, and this incision formed the anterior edge of the block that was taken coronally across the posterior half of the fontanelle. The skin was sutured to the rest of the block before processing. Blocks were decalcified with $10 \%$ formic acid, routinely processed and embedded in paraffin; 3 to 5 micron sections were stained with haematoxylin and eosin, and elastic van Gieson's stain.

\section{Results}

The gestational ages of the fontanelles are shown in table 1 .

\section{ANATOMY}

The fontanelle was defined laterally by the bony skull plates and so could not be delineated until 12 weeks' gestation when these first appeared.

From the lateral to the medial edges, the bony plates gave way to islands of bone and then to aggregates of plump fibroblasts surrounding pink osteoid like material. At the centre of the fontanelle no precursors of bone were present. The vertical structure of the fontanelle was best considered in levels: level 1 comprised the skin; level 2 comprised the connective tissue below level 1 and the bony skull plates; level 3 was the connective tissue between level 2 and the dura; and level 4 was the dura (fig la).

At 8 weeks' gestation level 1 (the skin) was a single layer of flat epithelial cells. This became stratified epithelium by 16 weeks, with a dermis containing hair follicles. By 19 weeks occasional sebaceous glands could be seen. By 23 weeks small clusters of fat cells had developed in the dermis. By 28 weeks a continuous layer of subcutaneous fat had developed; no major structural alteration occurred after this time. In levels 2 and 3 there were slight increases in the density of the collagen as gestation increased. Level 4 (dura) consisted of a single layer of cells until 28 weeks' gestation, when two layers of cells became visible. The distribution of elastin changed with increasing gestation; it was first seen as diffuse strands within dural vessels at $\mathbf{1 6}$ weeks, but a well defined elastic lamina had formed by 19 weeks' gestation. At this time wisps of elastin were seen in the connective tissue between levels 1 and 2 . By 23 weeks a well defined elastic membrane had developed at this point (fig lb). This membrane was present

Table 1 Gestational ages of the 19 fontanelles studied

\begin{tabular}{ll}
\hline $\begin{array}{l}\text { Gestational } \\
\text { age (weeks) }\end{array}$ & $\begin{array}{l}\text { No of } \\
\text { fontanelles }\end{array}$ \\
\hline 8 & 1 \\
$12-16$ & 5 \\
$19-22$ & 4 \\
$23-27$ & 4 \\
$28-52$ & 5 \\
\hline
\end{tabular}

Du Cane Road,

Accepted 28 November 1989 